\title{
HISTÓRIA E INVESTIGAÇÃO NA ESCOLA: A EXPERIÊNCIA DE FORMAÇÃO DO PROFESSOR-PESQUISADOR
}

\author{
HISTORY AND RESEARCH IN THE SCHOOL: THE TRAINING \\ EXPERIENCE OF THE TEACHER-RESEARCHER
}

Crislane Barbosa de Azevedo ${ }^{1}$

\begin{abstract}
RESUMO: Neste artigo apresentamos resultados de um projeto de formação de professores de História tomando por base a promoção de pesquisas em educação. Partimos do pressuposto da necessidade e viabilidade da formação do professor-pesquisador. As experiências em prol de tal formação foram desenvolvidas em atividades de estágio supervisionado na Universidade Federal do Rio Grande do Norte. Trabalhamos com orientação teórica acerca de pesquisa educacional com ênfase na pesquisa do tipo etnográfico bem como com direcionamentos práticos na definição do lócus da pesquisa (escola campo de estágio) e na elaboração dos projetos de investigação dos licenciandos tendo como foco o ensino de História. Apesar deste processo de formação tomando por base a pesquisa ser recente e ainda está em andamento, houve alunos que já apresentaram suas pesquisas em eventos e publicações da área. A proposta tem enfrentado diferentes entraves. Contudo, os resultados positivos mostram-se reais.
\end{abstract}

Palavras-chave: Formação docente. Ensino de História. Professorpesquisador.

\begin{abstract}
This paper presents results of a project for training teachers of History building on the promotion of research in education. We assumed the necessity and feasibility of teacher-researcher. Experiments in favor of such training activities were conducted in supervised internship at the Federal University of Rio Grande do Norte. We work with theoretical guidance about educational research with emphasis on ethnographic research as well as practical directions in defining the locus of the research (school training field) and the development of research projects of undergraduates focusing on the teaching of history. Although this training process building on the research is recent and is still underway, students were already presented their research on events and publications. The proposal has faced different obstacles. However, the positive results shown to be real.
\end{abstract}

Keywords: Teacher education. Teaching History. Teacher-researcher.

${ }^{1}$ Professora Adjunta do Departamento de Educação da Universidade Federal do Rio Grande do Norte.

História \& Ensino, Londrina, v. 2, n. 17, p. 339-359, jul./dez. 2011 
A formação do professor-pesquisador é recente no Brasil. Apesar disso, esse tipo de formação encontra-se difundida nas discussões educacionais contemporâneas. Há uma espécie de aceitação e consciência geral da necessidade de formarmos o professor que adota como base da sua prática a pesquisa. Porém, a forma de pormos em prática tal intento, muitas vezes não aparece. Dessa forma é que ressaltamos a necessidade de discutirmos caminhos e meios para a promoção dessa formação de um professor que efetivamente pesquisa, que é autônomo, reflexivo e crítico frente aos diversos aspectos e saberes da sua área de formação, assim como sobre o conhecimento dos seus alunos e do contexto mais amplo em que atua - escolas e comunidades.

Neste artigo, apresentamos os resultados iniciais (2008-2010) do desenvolvimento deste projeto de formação docente desenvolvido em atividades de Estágio Supervisionado em História na Universidade Federal do Rio Grande do Norte (UFRN) e que teve como pressuposto básico a necessidade e a viabilidade da formação do professor-pesquisador. A partir das reflexões sobre a formação do professor de História e da nova legislação sobre os estágios ${ }^{2}$ nas escolas, elaboramos um novo projeto para a formação de professores. Partimos da questão: como formar o professorpesquisador em História?

A última modificação ao projeto de formação de professores na Universidade Federal do Rio Grande do Norte (UFRN, 2006) ocorreu no primeiro semestre de 2008, acompanhando os debates recentes sobre o tema. Percebíamos a importância de levarmos aos alunos de Estágio Supervisionado em História a experiência da pesquisa no e sobre o ensino. Após discussões e planejamentos, decidimos pela oportunidade de levar os licenciandos, a partir do contato com a escola (campo de estágio), à elaboração de uma proposta de pesquisa, onde pudessem eles próprios, não apenas identificar uma problemática a ser investigada, mas também desenvolver a pesquisa, tendo eles próprios o papel de professorespesquisadores e investigadores da própria prática docente.

\footnotetext{
2 Com base na Resolução n. 02/2002, de 19 de fevereiro de 2002, do Conselho Nacional de Educação foram ampliadas as atividades de prática de ensino, na forma de estágio supervisionado, para 400 horas.
} 
Entre os objetivos do projeto destacamos a necessidade de levar o aluno-estagiário a ler e interpretar o cotidiano de uma realidade escolar bem como propor e executar um projeto de pesquisa em uma escola de Educação Básica. Para tanto, trabalhamos com orientação teórica e prática sobre pesquisa em educação com ênfase na pesquisa do tipo etnográfico, definição do campo de estágio e orientação para a elaboração de projetos de pesquisa individuais a serem desenvolvidos no ensino de História e tendo em vista as características dos campos de estágio. Após a execução dos projetos de investigação e análises dos dados, orientamos os alunosestagiários na elaboração de relatórios de docência e pesquisa cujos resultados possibilitem romper com dificuldades no processo ensinoaprendizagem da disciplina e possam materializar um percurso de formação docente marcado pela busca de uma emancipação profissional. Os relatórios finais do estágio se convertem em relatórios monográficos.

Ao acompanharmos os debates recentes sobre o tema, concordamos com Riani (1996), quando ao se referir aos estágios supervisionados, afirma que estes devem possibilitar

uma prática de reflexão sobre os problemas cotidianos da
realidade social. Daí a importância de ele ser trabalhado
também sob a forma de pesquisa, que se faz necessária para
esclarecer os problemas que a realidade apresenta,
propiciando uma reflexão que possa romper com a rotina e
possibilite alternativas de mudanças e transformações. (RIANI,
1996, p. 117-118).

A importância de formarmos o professor-pesquisador aparece frequentemente nas discussões educacionais contemporâneas e mesmo parece ter se tornado lugar comum. Marli André (1997) já registrou a ampliação da frequência com que tanto a literatura nacional quanto a internacional tratam sobre esse aspecto da formação. Concordamos com a autora quando afirmou também, em outra ocasião, que as atividades de pesquisa podem proporcionar, ao profissional da docência, meios para a sua reflexão sobre sua prática docente e para buscar formas que o ajudem a aperfeiçoar cada vez mais seu trabalho, proporcionando possibilidades de crescimento também a todos aqueles com quem trabalha. 


\section{Ensinar História pelo Caminho da Pesquisa}

Inicialmente, há graduandos que não vêem sentido no desenvolvimento de atividades de pesquisa em educação, uma vez que se intitulam como futuros professores de História. Parte dos alunos não consegue, de início, perceber que como professores de História, são eles também profissionais da educação. Diante de tal estado de coisas, buscamos trabalhar no sentido de deixar claro que o Estágio Supervisionado de Formação de Professores deve ir além da execução de um conjunto de aulas em um contexto escolar.

Diante dos desafios da profissão, da demanda da sociedade brasileira por melhorias educacionais, é importante e mesmo necessário que o Estágio possa se constituir em uma fonte de informações, de possibilidades de reflexão e ação e de aprofundamento no estudo das diversas questões relacionadas à educação. Para atingir tais fins, o licenciando precisará inserir-se no cotidiano escolar não com um projeto elaborado na universidade a priori, mas com um planejamento de intervenção construído a partir do que o futuro docente apropria acerca do cotidiano escolar e por meio deste cotidiano com o exercício de iniciação a uma prática de investigação. Como bem afirma Marilda Behrens "Compreender o dia-a-dia e traduzi-lo é função da pesquisa; socializar os resultados das pesquisas é função do ensino. No entanto, para operar a realidade como ela se produz e se reproduz é preciso estar inserido nela. E o estágio é a oportunidade desta primeira inserção" (apud RIANI, 1991, p. 91-92).

A pesquisa durante a formação docente é defendida por diversos profissionais (ANDRÉ, 1995; DEMO, 2004; FAZENDA, 1997; VEIGA, 2006). $O$ incentivo à pesquisa entre os estudantes de graduação, como registra Demo (2004, p. 103): "[...] tomando-se em conta nossa precariedade acadêmica histórica, a ideia tem de importante sair da rotina das aulas repetitivas e da tutela de professores que apenas reproduzem conhecimento de segunda mão". Os benefícios de atividades voltadas para a experimentação de situações concretas, a partir das quais os alunos em formação (docente) podem aprender a pesquisar sobre uma dada instituição de ensino, são inúmeros para o processo de profissionalização. 
Vale lembrar com Marli André, quando afirma que em relação a atividades de pesquisa durante a formação inicial de professores, que em termos de vantagens:

\begin{abstract}
Uma, bastante evidente, é a possibilidade de que o professoraluno venha a reproduzir em suas aulas o mesmo tipo de prática vivenciada em seu curso de formação. Outras vantagens [...] sensibilidade na observação, visão mais analítica da realidade, distinção entre as evidências e os próprios pontos de vista, atenção a propósitos não explicitados nas práticas e nos discursos, consciência do arbitrário e da possibilidade de múltiplas interpretações, [...]. (ANDRÉ, 2006, p. 129).
\end{abstract}

O curso de História da UFRN reformulou seu currículo, implementando as 400 horas de estágio supervisionado repartindo-as em quatro semestres. Como principal resultado obtido, a partir da nova organização para o Estágio I, II, III e IV no novo currículo do curso e visando o estabelecimento sistemático de pesquisas na área do ensino de História, elaboramos e implementamos a proposta para os Estágios no que se refere à prática de pesquisa descrita a seguir.

Podemos dizer que em um primeiro momento, no Estágio Supervisionado I, entre outros aspectos, o aluno-estagiário é levado ao campo de estágio onde tem a oportunidade de experimentar o lugar de observador participante, atento às dimensões institucional, pedagógica e sócio-econômica e cultural da instituição de ensino. Propomos, ao final, a elaboração de um relato de observação de tipo etnográfico. Neste, para além da descrição detalhada do visível, da análise documental e da coleta de informações por meio de depoimentos, entrevistas e conversas informais, o aluno-estagiário busca demonstrar o que está para além do explícito, em uma tentativa de captar os significados que os próprios sujeitos daquele cotidiano escolar observado atribuem às suas ações, interpretando e compreendendo assim a realidade educacional onde atuarão no Estágio Supervisionado II. Em meio ao processo de observação, o aluno é orientado no campo de Estágio e, principalmente, nas reuniões de Estágio 
ocorridas no campus-UFRN, a identificar uma problemática a ser investigada e a elaborar seu projeto de pesquisa ${ }^{3}$.

No segundo momento, Estágio Supervisionado II, buscamos melhor aproximar os futuros professores do contexto escolar a fim de que estes aprimorem suas concepções acerca da postura profissional a adotar e assim adquiram maior segurança e competência no trato das atividades de docência a serem desenvolvidas nos estágios seguintes da formação. Para tanto, orientamos os professores-estagiários a participar, efetivamente, da vida da escola e da comunidade onde ela está inserida tanto acompanhando reuniões pedagógicas e dos conselhos escolares, quanto elaborando e desenvolvendo projetos de integração escola/comunidade - organização de grupos de estudos com pais, alunos e professores; oferta de mini-cursos; organização de eventos culturais, oficinas temáticas, palestras, entre outras possibilidades de ações de intervenção. Tal aproximação proporciona meios para que os futuros professores-pesquisadores amadureçam os projetos de pesquisa a serem executados no semestre seguinte com o intuito de melhorá-lo para a experimentação efetiva e futura com uma turma de alunos do Ensino Fundamental.

No terceiro momento, Estágio Supervisionado III, além do desenvolvimento da prática docente exercida no Ensino Fundamental, o estagiário é levado à aplicação do projeto em sala de aula, para o qual conta com orientação tanto no campo de estágio quanto no campus-UFRN em reuniões individuais e coletivas agendadas no início do estágio. Nesta

\footnotetext{
3 São exemplos de projetos elaborados (títulos) em 2009.2 - Como utilizar filmes para melhorar o ensino de História; Ensino de História e história oral; A utilização da música no ensino de História; $\mathrm{O}$ uso de charges no ensino de História; Aprendendo com a técnica estudo dirigido; O ensino de História através do auxílio de documentários; Documentos escritos em sala de aula: repensando uma antiga possibilidade; Internet e Educação: o ensino de História por meio de blogs; $\mathrm{O}$ uso de cinema e a construção do estereótipo: possibilidades de aprendizagem em História; Interpretação de texto do livro didático no ensino de História; A utilização de documentários como recurso didático na prática do ensino de História; Diga XIS: a utilização da fotografia como ferramenta didáticopedagógica e reflexiva no ensino de História; Da história local e do cotidiano no ensino de História ao processo de transferência aluno-professor na psicanálise; Imagem: parte integrante do ensino de História; Alfabetização cultural: o ensino de História e o patrimônio cultural na Educação Básica; Textos on-line: o uso de documentos digitais no ensino de História; O ensino de História através do recurso cinematográfico; O ensino de História através de textos para-didáticos; Fotografia e ensino de História: um novo modo de entender o mundo; O uso de história oral no ensino de História; Cinema: um documento histórico, historiográfico e didático; Uma releitura da história em sala de aula: aprendizagem significativa por meio de conceitos; Representações teatrais e ensino de História; Imprensa escrita nas aulas de História.
} 
fase, registra as atividades e observações feitas em diário de campo. Nesse momento, os alunos são orientados a realizar a primeira sistematização dos dados e a elaborar um ensaio onde são apresentados os primeiros resultados da investigação.

Como fruto de uma pesquisa, a produção científica dos alunosestagiários é orientada a atender às normas técnicas próprias dos textos científicos. O texto organizado em introdução, desenvolvimento e conclusão precisa, inicialmente, apresentar o objeto de estudo, justificando a sua relevância, o problema e os objetivos da investigação, metodologia, elementos teórico-conceituais, o lócus da pesquisa, seu público-alvo e a sua base empírica. No desenvolvimento do texto é preciso contextualizar o trabalho; explicar os possíveis ajustes teórico-metodológicos necessários à execução da investigação; explicitar detalhadamente o percurso seguido na coleta e análise dos dados bem como na construção dos argumentos relativos aos objetivos e à questão (problema) da pesquisa; e, indicar os resultados atingidos, para somente, a partir de então, apresentar as conclusões da pesquisa.

No Estágio Supervisionado IV, o aluno além do exercício docente praticado em uma turma de Ensino Médio, é orientado a realizar a sistematização final dos dados, interpretando-os à luz de leituras de autores da área, a fim de elaborar o seu próprio texto, refletindo ao mesmo tempo sobre as possibilidades de novas práticas para a docência em História. Ao final das atividades de estágio, os relatos acerca da prática docente e a análise da investigação convertem-se em um relatório monográfico e os alunos são orientados para a exposição oral dos resultados das experiências. Com o intuito de romper com uma rotina docente descontextualizada, esperamos, assim, que o professor-estagiário transforme sua prática em uma dinâmica de trabalho onde a construção do conhecimento via pesquisa torne-se uma possibilidade concreta incorporada ao futuro exercício profissional.

O trabalho de formação do docente em História pautado na pesquisa objetiva, principalmente, a melhoria do ensino da disciplina pelo caminho da instrumentalização do futuro professor sobre as especificidades da pesquisa 
educacional e os meandros de um cotidiano escolar. Este novo docente deverá ser capacitado a: observar uma realidade escolar em seus aspectos administrativos e pedagógicos; redigir um relato de tipo etnográfico com os resultados da sua observação; levantar uma questão de pesquisa sobre a realidade escolar observada e descrita; apropriar-se de uma bibliografia sobre a problemática de pesquisa por ele levantada; definir objetivos para o trabalho de investigação; apresentar meios para a obtenção de respostas à questão de pesquisa; aplicar o projeto de pesquisa durante uma unidade de ensino, correspondente em geral a um bimestre de aulas; coletar, sistematizar e analisar informações; redigir relato sobre os resultados da aplicação do seu projeto de investigação; e, propor novas estratégias metodológicas para um efetivo e contextualizado ensino de História.

De forma mais específica, podemos afirmar que as pesquisas apóiamse na perspectiva da pesquisa de tipo etnográfico. Nesta situação, o que se busca é descrever, compreender e interpretar os fenômenos educativos que ocorrem em contextos escolares. Na perspectiva etnográfica, as diversas variáveis que envolvem a prática pedagógica são analisadas em conjunto e na sua dinamicidade. Dessa maneira, torna-se possível melhor compreender o cotidiano escolar. Para tanto, é preciso considerar a atuação do pesquisador como um observador, entrevistador e analista entre teoria e empiria.

De acordo com André (1989) o que mais caracteriza a pesquisa de tipo etnográfico é: a) um contato direto e prolongado do pesquisador com a situação e as pessoas ou grupos selecionados, deixando claro o grau de envolvimento e participação do pesquisador na situação investigada; b) a obtenção de uma grande quantidade de dados descritivos sobre a realidade estudada, em função da qual faz suas análises e interpretações; c) a utilização de diferentes técnicos de coleta de dados; d) flexibilidade entre observação e análise, entre teoria e empiria.

A atenção à descrição é uma referência às técnicas metodológicas das pesquisas de tipo etnográfico em uma perspectiva antropológica (GEERTZ, 2008), a qual ganhou espaço no Brasil, em meio às pesquisas educacionais, 
na década de $1970^{4}$ e que, fundamentam grande parte das pesquisas desenvolvidas no Estágio Supervisionado de Formação de Professores de História da UFRN.

Características da etnografia contribuem metodologicamente para a pesquisa acerca de situações escolares ao possibilitar ao pesquisador a adoção de uma postura aberta e flexível durante a coleta e a análise dos dados possibilitando fazer ajustes na investigação tendo em vista uma melhor análise e compreensão das práticas pedagógicas e, em âmbito maior, o cotidiano escolar. Em outras palavras, tal flexibilidade deve ser utilizada para ampliação e enriquecimento teórico e não como pretexto para justificar falta de um caminho teórico preestabelecido.

Nesse sentido, quem pesquisa precisa ir além dos seus próprios valores e pressupostos para penetrar no universo do outro, interpretando-o e compreendendo-o. Nesse sentido, os resultados da coleta de dados (observações, entrevistas, documentos escritos etc.) seriam meios através dos quais o investigador aproximar-se-ia do universo dos investigados. A busca pelo extrapolar de seus próprios sentidos e significados por meio da pesquisa de tipo etnográfico nas atividades de estágio supervisionado visa a levar os estagiários a analisar o cotidiano escolar de forma clara, desprovida de preconceitos, pressuposições e observações do senso comum, desenvolvendo, dessa maneira, uma análise contextualizada e, portanto, mais fidedigna acerca do que efetivamente ocorre em um contexto escolar.

Por meio da iniciação à pesquisa em educação a partir de tal perspectiva, buscamos, na experiência desenvolvida, atualmente, na UFRN, que os futuros professores experimentem a possibilidade de aprender a observar e a sistematizar o resultado de suas observações de modo a, por meio dele, ser possível a formulação de uma questão de pesquisa, a partir da qual deverá estudar sobre a produção bibliográfica relativa ao tema a ser investigado e definir um planejamento para a investigação, pensado teórica e metodologicamente. Dessa forma, concordamos com Riani quando afirma que:

\footnotetext{
${ }^{4}$ A etnografia originou-se na Antropologia de Franz Boas, compreendida em uma visão metodológica de simples coleta de dados. A ausência de vinculações teóricas do início modificou-se com teóricos como Malinowski na década de 1920. A vinculação entre teoria e metodologia ganhou nova orientação com Geertz nos anos de 1970.
} 
O estágio poderá se constituir em uma fonte de informações, de possibilidades de reflexão e ação e de aprofundamento no estudo das diversas questões relacionadas à educação. Mas, para atingir esses objetivos, o aluno precisará inserir-se nesse cotidiano que a parte prática de sua formação lhe oferece não com um projeto pronto e acabado, mas com um construído a partir do cotidiano e através dele com o exercício de iniciação à pesquisa. (RIANI, 1996, p. 120).

Há licenciandos que têm dificuldade em analisar seriamente o espaço da sala de aula e da escola no seu todo e vêem somente defeitos. O resultado disso, por vezes, tem sido a construção de críticas superficiais que, em geral, pouco colaboram com o professor da classe na compreensão do ensino da disciplina. O estágio sob a forma de pesquisa visa, entre outros aspectos, contribuir para que tais graduandos analisem melhor e compreendam de forma contextualizada os problemas verificados nas escolas. Muitos dos quais estão para além das possibilidades de determinados docentes de História.

Nesse sentido, a experiência na UFRN vivenciada nos anos de 2008 e 2010 apresentou bons resultados junto aos licenciandos, são exemplos: alunos mais atentos ao cotidiano escolar (campo de estágio); melhoria na capacidade de problematização da realidade; preocupação na delimitação de um problema de pesquisa; consciência da necessidade de remanejamento de práticas tendo em vista a adequação destas à realidade; clareza sobre a importância do professor manter-se atualizado; consciência de que é necessário inovar sem perder de vista a explicação histórica que requer por sua vez uma sólida base de conhecimentos sobre os conteúdos da disciplina História; e, ciência da importância da contextualização dos conteúdos, das práticas, das análises e críticas feitas sobre a escola e seus agentes. Para atingirmos tais resultados foi necessário, obviamente, que os graduandos compreendessem a importância da sua formação como um professor-pesquisador e, consequentemente, sentissem-se envolvidos em um processo de criação e orientação proporcionado pelo professororientador.

Por meio dos estágios, podemos orientar os alunos, despertando-os para a pesquisa, estimulando a criatividade e o senso crítico dos estagiários, 
incentivando-os ao desenvolvimento de ações dinâmicas e proveitosas. No entanto, para tornar os estágios uma atividade coerente, compatível com a realidade e instrumentalizadora para uma autonomia docente nos futuros professores, é preciso, antes de mais nada, trabalhar com grupos pequenos. Tal aspecto, infelizmente, inexiste na UFRN. De acordo com as normas que regulamentam o Estágio Supervisionado na instituição: "É limitada a quantidade de 25 (vinte e cinco) estagiários por orientador de estágio" (UFRN, Portaria n. 09, Art. 15, 2008). Contudo, o que temos vivido a cada semestre nos últimos dois anos, é o trabalho de orientação e acompanhamento de número quatro vezes maior, tornando sobre-humano o trabalho do orientador de estágio.

São vários os obstáculos no desenvolvimento de atividades formadoras que tomam por base a orientação para a pesquisa. Do ponto de vista institucional, como exemplifica o problema acima, podemos citar o elevado número de alunos a serem orientados por um único professor e a falta de uma instituição-laboratório para o desenvolvimento dos estágios (Colégio de Aplicação) na universidade. Esse fato leva o trabalho dos estágios a ser desenvolvido em várias escolas da rede pública de ensino, inclusive, distantes entre si espacialmente, dificultando sobremaneira o acompanhamento e o suporte presencial a todos os estagiários nas escolas por parte do professor-orientador.

Entre os principais obstáculos podemos citar ainda, desta vez por parte dos alunos, as dificuldades destes na definição do problema a ser investigado e na articulação deste com objetivos e referencial teóricoconceitual de pesquisa. Muitos confundem, durante bastante tempo, problema de pesquisa com problemas da escola ou da educação brasileira de modo geral, pronunciando-se, por exemplo, da seguinte maneira: "Os problemas percebidos para a pesquisa foram a falta de interesse e uma deficiência no aprendizado de história pelos alunos", ou ainda: "O problema da minha pesquisa é que os alunos da escola são desmotivados e não há um apoio dos membros da escola para eles e assim minha pesquisa fica difícil de ser feita". 
As dificuldades de escrita apresentadas por alguns dos discentes também se apresenta como um entrave. Tais dificuldades, de certo, são heranças da escola básica, mesmo que os alunos não tenham muita consciência disso.

As dificuldades de escrita, por vezes, têm produzido textos fragmentados e pouco claros, constituindo-se na famosa "colcha de retalhos" como os próprios alunos os denominam. Os obstáculos podem ter origem também nos problemas de compreensão e de interpretação de textos. A falta do hábito de escrever e de modo especial, de escrever textos próprios pode também ser considerado foco de origem das dificuldades de se expressar por meio do escrito. Esse aspecto pode ser evidenciado quando o aluno consegue expressar-se bem oralmente, desenvolvendo coerentemente seu raciocínio, mas sem o mesmo êxito em textos escritos por menor que sejam.

Outra consideração de ordem qualitativa evidenciada na aplicação deste projeto de formação docente foi a enorme dificuldade para que os estagiários elaborassem projetos de pesquisa para a investigação de como se ensina História. Isto se tornou visível na leitura dos projetos apresentados. Em geral, os alunos do curso de História quando pensam em projeto de pesquisa imaginam investigar sobre conteúdos da História. A compreensão de que um professor de História pode realizar pesquisa sobre o ensino que pratica, sobre a aprendizagem efetivada por seus alunos, sobre como se ensina História na realidade escolar, sobre o que significa estudar História para um aluno do Ensino Fundamental e Médio, não é percebida pelos estagiários, mesmo quando estão exercendo a função docente na rede municipal e estadual. Quando foram orientados para buscar os dados da pesquisa na sala de aula em que fariam o estágio, a maioria confundiu projeto de pesquisa com projeto pedagógico e em alguns casos até mesmo com plano de aula. A ausência de parte dos alunos nas reuniões de orientações (plantões de orientação na UFRN), obviamente, contribuiu para problemas apresentados por alguns deles.

Em meio às atividades de Estágio buscamos que o licenciando conscientize-se de que seus princípios teórico-metodológicos, enquanto 
profissional da docência, precisam ser definidos e, constantemente, aprimorados em meio às dificuldades da profissão. E assim, percebam a viabilidade da promoção de ações interativas e respeitosas na comunidade escolar assim como novas possibilidades de práticas pedagógicas que priorizem o alcance dos objetivos de aprendizagem e não a absorção mecânica de conteúdos e a compulsão disciplinar.

Ler uma realidade e interpretá-la com base no que aprendeu na graduação, sendo possível assim a articulação entre teoria e prática, propondo (projeto) novas metodologias, ações, reflexões, são meios para que o futuro profissional se conscientize da importância social do seu papel de professor de História. Buscamos ainda que esse futuro professor adote como pressupostos a necessidade de construção e demonstração de uma visão crítica e interpretativa sobre a realidade educacional e a importância de fazer da sua prática um processo contínuo de investigação.

Muitos alunos sentem-se inseguros diante da proposta de trabalho com base em pesquisa. A busca velada por respostas prontas acerca dos problemas ocorridos nas escolas, ainda que em pequeno número, aparece entre os alunos. Trabalhamos com o intuito de mostrar que não existem caminhos preestabelecidos e receitas prontas que possam conduzi-los objetivamente no trabalho de sala de aula bem como na pesquisa em educação. Buscamos mostrar que, em algumas ocasiões, as decisões precisam ser tomadas ao longo do processo, com atenção e muito cuidado, tendo em vista a necessidade de responder aos impasses que vão surgindo. A inexistência de um receituário, contudo, não invalida a existência de caminhos possíveis. No que se refere, especificamente, à pesquisa em educação, pré-requisitos são necessários. Seja qual for o problema da pesquisa ou os elementos teórico-conceituais, uma investigação exige o atendimento de três requisitos: a existência de uma pergunta que se buscará responder (problema); a definição e a explicação das etapas do trabalho que permitam ao pesquisador obter as respostas necessárias; e, a demonstração das respostas de forma consistente e confiável.

Houve, portanto, alunos-estagiários que demonstraram grande dificuldade de agir de maneira ativa e autônoma. Parte dos discentes 
demonstrava facilidade em indicar e criticar, inclusive no curso de formação em História na universidade, a presença de professores reprodutivistas, com programas, aulas e instrumentos de avaliação repetidos ano a ano de docência. Mas, percebemos que ao trabalhar o estágio supervisionado de formação de professores tomando por base a prática de pesquisa e, portanto, baseada na construção do conhecimento com participação direta dos discentes, parte destes, no início dos trabalhos, rejeitaram a proposta ao não conseguirem perceber o sentido. Essa atitude de parte dos alunos de História da UFRN torna-se compreensível ao analisarmos a história da educação brasileira, mais especificamente, no que se refere ao ato de ensinar.

O ensino formal pode ser, em grande medida, caracterizado no Brasil pela presença de correntes pedagógicas tradicionais e renovadas. Estas últimas caracterizam-se pela promoção do pensamento divergente, voltado para a problematização do conhecimento e para a prática de experiências desafiantes em prol da aprendizagem. Seus princípios adotados por nós nas atividades de estágio na UFRN baseiam-se em situações complexas e mal definidas e o que se busca é o desenvolvimento de um pensamento criativo e inovador. Disso decorre que a inovação dentro da universidade ocorre nos processos de aprender, ensinar e pesquisar.

A feliz inexistência de receitas prontas aponta as práticas de pesquisa, durante a formação inicial do professor, como uma premissa urgente a ser adotada nos cursos de formação. É preciso desenvolver junto aos licenciandos o compromisso do "ir além" dos livros que leram, das opiniões que ouviram, dos problemas com os quais já se depararam, das possibilidades que lhes foram oferecidas. A formação dos futuros professores, nesse sentido, gira em torno da busca pela conquista da autonomia docente. Tal conquista consiste em uma tarefa individual daqueles que buscam obter um conhecimento mais elaborado e uma postura profissional mais sólida e respeitável. Formar o professorpesquisador significa isso.

A realização de uma proposta de ensino que toma por base 0 exercício da pesquisa tem se mostrado assim não apenas importante e 
necessária, mas também possível. Para tanto, de certo, parte do pressuposto do rompimento com as concepções científicas de ensino de filiação positivista, para as quais a pesquisa é tarefa neutra e de acesso restrito apenas aos especialistas e, portanto, deslocada da prática social. Implica também o rompimento com a concepção de escola e ensino como meros reprodutores de saberes, ideias e valores produzidos em outras esferas. A dinâmica escolar produz conhecimentos que Ihes são próprios e estes penetram na cultura daqueles que, mesmo apenas indiretamente, envolvem-se com ela. Os professores devem ser os difusores de tais conhecimentos, concebendo uma postura intelectual como inerente à sua profissão. Por meio da atual proposta de formação em Estágio Supervisionado de Formação de Professores em História objetivamos instrumentalizar os futuros docentes em História para tanto.

Apesar dos resultados satisfatórios que uma experiência como esta pode acarretar aos envolvidos, o professor-orientador deve estar ciente dos limites que envolvem tais ações, a começar pela concepção de pesquisa adotada. A prática de investigação desenvolvida nos estágios supervisionados apresenta limitações resultantes de aspectos referentes a prazos para execução de projeto, que devem atender ao cronograma oficial do semestre letivo, assim como no que se refere ao suporte material e financeiro da pesquisa e também no que concerne ao reconhecimento institucional dificilmente visível tanto para quem executa quanto para quem orienta esse tipo de pesquisa. Em outros termos, o ato de pesquisar contraria determinações temporais fortemente estanques como as que marcam as disciplinas acadêmicas. O trabalho com carga-horária determinada, o que marca as atividades de estágio supervisionado, denota um cenário que se confronta com os princípios de investigação. Professoresformadores e alunos-estagiários devem estar conscientes da inexistência de uma fonte de recursos na universidade que auxilie as atividades de pesquisa dentro dos Estágios, sendo assim os custos da pesquisa tornam-se uma responsabilidade de seus executores.

Apesar de tais dificuldades juntamente com o problema da (in)visibilidade institucional, a nosso ver, não diminuem a importância desse 
projeto de formação docente, tendo em vista a continuidade do processo de investigação. Esta se torna marcada pela reflexão, criação, avaliação e promoção de novas práticas por parte de todos os envolvidos com o processo da pesquisa. Acreditamos assim que o professor que pesquisa, que investiga a realidade de seus alunos, que reflete sobre a própria prática em sala de aula, que problematiza e contextualiza os conteúdos junto ao seu público discente, que relaciona presente e passado durante os trabalhos escolares, que observa, recolhe e analisa dados acerca de uma realidade problemática, ou seja, que experimenta e colhe resultados positivos de uma atividade investigativa em educação, não conseguirá retroceder facilmente na sua prática docente cotidiana adotando uma rotina de trabalho distante dos alunos e, portanto, certamente fragmentada e descontextualizada, sem relação com a vida dos estudantes da Educação Básica.

Esse direcionamento para a pesquisa em educação na formação inicial do docente, sem dúvida contribui para melhorias no exercício da docência e da pesquisa sobre o ensino de História na Educação Básica bem como para a consolidação de um programa para a formação de professores na UFRN.

O processo de validação da produção acerca da pesquisa no ensino de História requer demonstração escrita e oral. Ao final dos trabalhos de investigação é preciso materializar os resultados da pesquisa. Dessa maneira, mesmo diante de entraves e da pouca visibilidade institucional das atividades de pesquisa desenvolvidas nos Estágios, os alunos-estagiários são orientados a publicar seus trabalhos, pondo à validação pública suas experiências de docentes em formação.

O estágio supervisionado não pode ser considerado um momento pontual da formação, um complemento da formação profissional ou uma atividade complementar para conclusão do curso. Ele deve ser entendido como um componente total do curso, constituído e constituinte das dimensões do ensino, da pesquisa e da extensão. Buscamos trabalhá-lo como um espaço político-pedagógico privilegiado de construção da práxis, posto que possibilita a inserção do licenciando no mundo do trabalho docente e na prática social, estimulando a reflexão e a criatividade, a 
construção do conhecimento sobre a sua profissão e a sensibilização de docente para o atendimento das demandas sociais.

Dessa maneira é que a proposta de estágio em História na UFRN está vinculada à ideia de desenvolvimento de atividades voltadas para o atendimento à comunidade, as quais deverão proporcionar a inserção do estagiário na realidade, para que possa perceber os desafios que a carreira docente Ihe oferecerá e possa, assim, refletir maduramente sobre a profissão que vai assumir e em confronto com a realidade, passar a questionar, a dialogar, a interagir, a se comunicar e a construir o seu conhecimento. Dessa forma, o estágio supervisionado poderá auxiliar o aluno a compreender e a enfrentar o mundo do trabalho e contribuir para a formação de sua consciência política e social, unindo a teoria à prática,

Apesar deste processo de formação do professor tomando por base a pesquisa em educação ser recente e ainda está em andamento na UFRN, houve alunos que já apresentaram suas pesquisas em eventos ${ }^{5}$ e publicações da área ${ }^{6}$. A produção dos graduandos motivou alguns deles, envolvidos na comissão organizadora da "II Semana de Estudos Históricos", em 2008, a requerer a presença do simpósio temático intitulado "História e Educação"7 . Neste, alunos do curso de História apresentaram resultados de pesquisas desenvolvidas durante o Estágio Supervisionado de Formação de Professores. Os autores, a partir dos projetos executados em turmas de Ensino Fundamental, refletiam acerca das suas experiências como professores-estagiários e demonstravam a articulação entre ensino e

\footnotetext{
5 Alunos participaram, por exemplo, em 2008 do II Encontro Internacional de História Colonial; do $5^{\circ}$ Seminário Educação e Leitura na UFRN; e em 2009, do XXV Simpósio Nacional de História, realizado na Universidade Federal do Ceará, da XVIII Semana de Humanidades do Centro de Ciências Humanas, Letras e Artes, e da XV Semana de Pesquisa do Centro de Ciências Sociais Aplicadas da UFRN. Ver, por exemplo: LIMA JÚNIOR, 2009 e OLIVEIRA, 2009.

6 Revista Fazendo História, Natal, ano 2, n. 3, 2009. Neste número da revista foram publicados os seguintes artigos de alunos de Estágio Supervisionado em História da UFRN: Ensinar história: o papel do professor, de Marlos Magno G. de Menezes; A exclusão do incluído: a busca pelo equilíbrio, de Ana Cristina O. da Silva e Vanda Sarmento B. Mesquita; A construção do racismo no Brasil e seus efeitos na atualidade, de Eduardo Fernandes S. G. Sena; O aprendizado escolar através da imagem no livro didático de História: uma experiência, de Genilson de Azevedo Farias; e, A importância da leitura no ensino de História, de Paula Lorena C. Albano.

7 Evento ligado ao Departamento de História da UFRN. A experiência bem sucedida resultou na permanência do simpósio temático na "III Semana de Estudos Históricos", realizada em outubro de 2009.
} 
pesquisa em prol de melhorias no ensino de História na Educação Básica. Nessa perspectiva de trabalho formativo torna-se, assim, possível aos professores em formação, a divulgação de seus trabalhos iniciais por meio não apenas da exposição das atividades realizadas, mas também do significado que professores e alunos atribuíram às experiências escolares vividas.

Nesse sentido é que os resultados desses trabalhos na UFRN têm demonstrado possibilidades de rompimento com dificuldades no processo ensino-aprendizagem da disciplina e a materialização de um percurso de formação docente marcado pela busca de uma emancipação profissional. A produção, fruto de tais trabalhos tem sido incorporada à bibliografia básica do curso de estágio em História na UFRN servindo de material para discussão sobre formação de professores.

Dessa forma, é que advogamos que para além da discussão sobre a importância da formação do professor-pesquisador, precisamos apresentar resultados de ações concretas que demonstrem a viabilidade desse tipo de formação para que assim possamos aprofundar ações formativas. Neste trabalho, ao invés de explicarmos a importância da pesquisa ou como se faz uma pesquisa, demonstramos resultados de um processo no qual decidimos envolver o licenciando de História em uma pesquisa acerca do como ensinar e do como se aprende História. Acreditamos que só a partir de uma formação docente tomando por base o exercício da pesquisa sobre a própria prática, teremos condições de dar os suportes necessários aos futuros professores para que construam a sua identidade profissional, tendo claras as dimensões do seu papel de docente.

É importante deixarmos claro que o grande objetivo do desenvolvimento desse projeto de formação de professores de História aqui explicitado, não é a promoção de pesquisas científicas no sentido estrito do termo, pela simples constatação da incompatibilidade entre as exigências de pesquisas acadêmicas com as características dos estágios supervisionados. O que buscamos é a iniciação dos futuros professores no desenvolvimento de práticas de investigação acerca do cotidiano escolar dentro de uma preocupação didática com a formação de profissionais da educação. 
Buscamos que tais profissionais qualifiquem-se adotando uma postura detentora de um mínimo de ações intelectuais.

As circunstâncias que os professores enfrentam e são obrigados a resolver apresentam características diversas e, ao mesmo tempo, únicas, exigindo respostas rápidas e, simultaneamente, conscientes, diversas e também, únicas. O domínio seguro desse universo complexo torna-se possível apenas com o profissional que reflete sobre a (e na) ação. A iniciação à pesquisa sobre o cotidiano escolar durante a formação docente inicial é condição relevante para a promoção desse professor reflexivo. Buscamos que os futuros docentes experimentem o lugar de participantes de um saber que se constrói e reconstrói a todo o instante e compreendam a complexidade do seu campo de trabalho. Em termos mais específicos, buscamos, por meio dessa perspectiva de orientação da formação docente, que os novos professores sintam-se capacitados a examinar o seu próprio ensino, com vistas a uma mudança nas práticas em prol do êxito dos objetivos de aprendizagem dos seus futuros alunos.

\section{Considerações Finais}

Por meio deste projeto de Estágio Supervisionado em História na UFRN buscamos trabalhar a prática de ensino criando condições para que o futuro docente se conscientize da importância social do seu papel, posicionando-se criticamente perante o seu próprio conhecimento, percebendo suas limitações e as consequências daí decorrentes e adquirindo um instrumental para tratar esse conhecimento como objeto de ensino e pesquisa, fazendo da sua própria prática pedagógica um processo de investigação permanente.

Buscamos transformar a experiência do estágio em algo verdadeiramente relevante e útil para os alunos, revertendo o papel de atividade de segunda classe, que gozou durante décadas no Brasil, para algo indispensável ao processo de ensino-aprendizagem. Com esse intuito defendemos que o estágio poderá ser desenvolvido através de uma nova metodologia, na qual a construção de projetos de ação possa contemplar as 
funções ensino, pesquisa e extensão, partindo do conhecimento dos alunos e fundamentando-se nos dados teóricos adquiridos, de modo a interagir com os interesses da comunidade.

Objetivamos, ao final, contribuir para que os alunos, professoresestagiários, desenvolvam condições de refletir sobre uma experiência pedagógica completa e assim possam tornar-se promotores da própria formação. Esperamos que os futuros docentes gerem reflexões e aprendizagens coletivas, principalmente, dentro das suas escolas, sejam agentes orientadores das suas próprias práticas, adquiram maior poder político e visibilidade social.

Buscamos que o graduando questione a realidade escolar que observa. A ação de questionar, problematizar a partir minimamente de um referencial teórico, leva ao ato de comprometimento, posto que se caracterizará por ser explicada, argumentada e assim, produtiva, conectada à realidade. Sem questionamentos, o futuro professor tende a aceitar o conhecimento sobre a educação escolar de forma limitada. A partir do momento que se passa a questionar de forma sistemática e responsável os eventos, o docente passa a buscar sempre novas alternativas de ação.

\section{Referências}

ANDRÉ, M. E. D. A. de. A pesquisa no cotidiano escolar. In FAZENDA, I. (Org.). Metodologia da pesquisa educacional. São Paulo: Cortez, 1989, p. 35-45.

. Etnografia da prática escolar. São Paulo: Papirus, 1995.

- Avanços no conhecimento etnográfico da escola. In FAZENDA, I. (Org.). A pesquisa em educação e as transformações do conhecimento. 2 ed. Campinas: Papirus, 1997, p. 99-110.

- Ensinar a pesquisar: como e para quê?. In VEIGA, I. P. A. V. (Org.). Lições de didática. Campinas: Papirus, 2006, p. 123-134.

DEMO, P. Iniciação científica: razões formativas. In MORAES, Roque de; LIMA, Valderez M. do R. (Org.). Pesquisa em sala de aula: tendências para a educação em novos tempos. 2 ed. Porto Alegre: EDIPUCRS, 2004, p. 103126. 
FAZENDA, I. (Org.). A pesquisa em educação e as transformações do conhecimento. 2 ed. Campinas: Papirus, 1997, p. 99-110.

GEERTZ, C. A interpretação das culturas. Rio de Janeiro: LTC, 2008.

LIMA JÚNIOR, D. L. A História trabalhada quadro a quadro. SEMANA DE PESQUISA DO CCSA DA UFRN. Anais da XV Semana de Pesquisa do Centro de Ciências Sociais Aplicadas da UFRN. Natal: UFRN, 23 a 25 de setembro de 2009.

OLIVEIRA, H. R. S. de. Entre história(s), músicas e representações: representação dos alunos sobre a utilização de música como nova linguagem no ensino de história. SEMANA DE PESQUISA DO CCSA DA UFRN. Anais da XV Semana de Pesquisa do CCSA da UFRN. Natal: UFRN, 23 a 25 de setembro de 2009.

REVISTA FAZENDO HISTÓRIA: Em questão - o ensino de História. Natal, ano 2, v. 3, 2009. http://www.cchla.ufrn.br/fazendohistoria/edicao3.php

RIANI, D. C. Formação do professor: a contribuição dos estágios supervisionados. São Paulo: Lúmen, 1996.

UNIVERSIDADE FEDERAL DO RIO GRANDE DO NORTE. Projeto de Estruturação dos campos de estágio para a formação de professores de Educação Básica. Natal: Departamento de Educação/Coordenação das Licenciaturas, 2006.

- Portaria $n^{\circ}$. 09/2008, de 10 de junho de 2008 - Institui o Regulamento das Atividades Especiais Coletivas Estágios Supervisionados de Formação de Professores nos cursos de licenciatura da Universidade Federal do Rio Grande do Norte, campus central. Natal: Pró-Reitoria de Graduação, 2008.

VEIGA, I. P. A. V. (Org.). Lições de didática. Campinas: Papirus, 2006. 